\title{
BACTERIOLOGICAL PROFILE OF LATE ONSET NEONATAL SEPSIS IN A BRAZILIAN NEONATAL INTENSIVE CARE UNIT

\section{BACKGROUND AND AIMS}

Late-onset neonatal sepsis is a healthcareassociated infection and a major cause of neonatal mortality, with the incidence of 1-5:1000 newborns. Risk factors for this disease include prematurity, low birth weight, use of central venous catheters and other devices.

\section{METHODS}

This was a retrospective study, conduced in the Hospital "Irmandade da Santa Casa de Misericórdia de São Paulo"/Brazil, from January/2011 to December/2016. We conducted a retrospective descriptive study performed on a Brazilian NICU from January/2011 to December/2016. We included all newborns in NICU with late-onset neonatal sepsis and bacteremia.

\section{RESULTS}

The admission rate in this NICU is around 300 newborns per year. The cohort was 107 newborns admitted in NICU, which had 147 episodes of late-onset neonatal sepsis during the six years study. The mean gestational age was 31.6 weeks (95\% Cl 30.7-32.5 weeks); the frequency of low birth weight was $82.2 \%(n=89)$, and the lethality rate was $26.2 \%(n=28)$ in 30 days. Invasive devices were used in $79.4 \%(n=85)$ and parenteral nutrition was received in $70.1 \%(n=75)$ of the newborns. The most prevalent etiology was Coagulase-negative Staphylococcus (CNS) with $40.5 \%(n=60)$ of cases and $71.7 \%(n=38)$ oxacillin resistance. The second most prevalent etiologic agent was Klebsiella with $29.7 \%(n=44)$ of cases and $54.5 \%(n=24)$ extended-spectrum beta-lactamase. Only one of the gramnegative bacteria was carbapenem-resistant.

GRAPHIC2: Number of oxacillin resistant Coagulasenegative Staphylococcus strains between 2011 and 2015 (n)

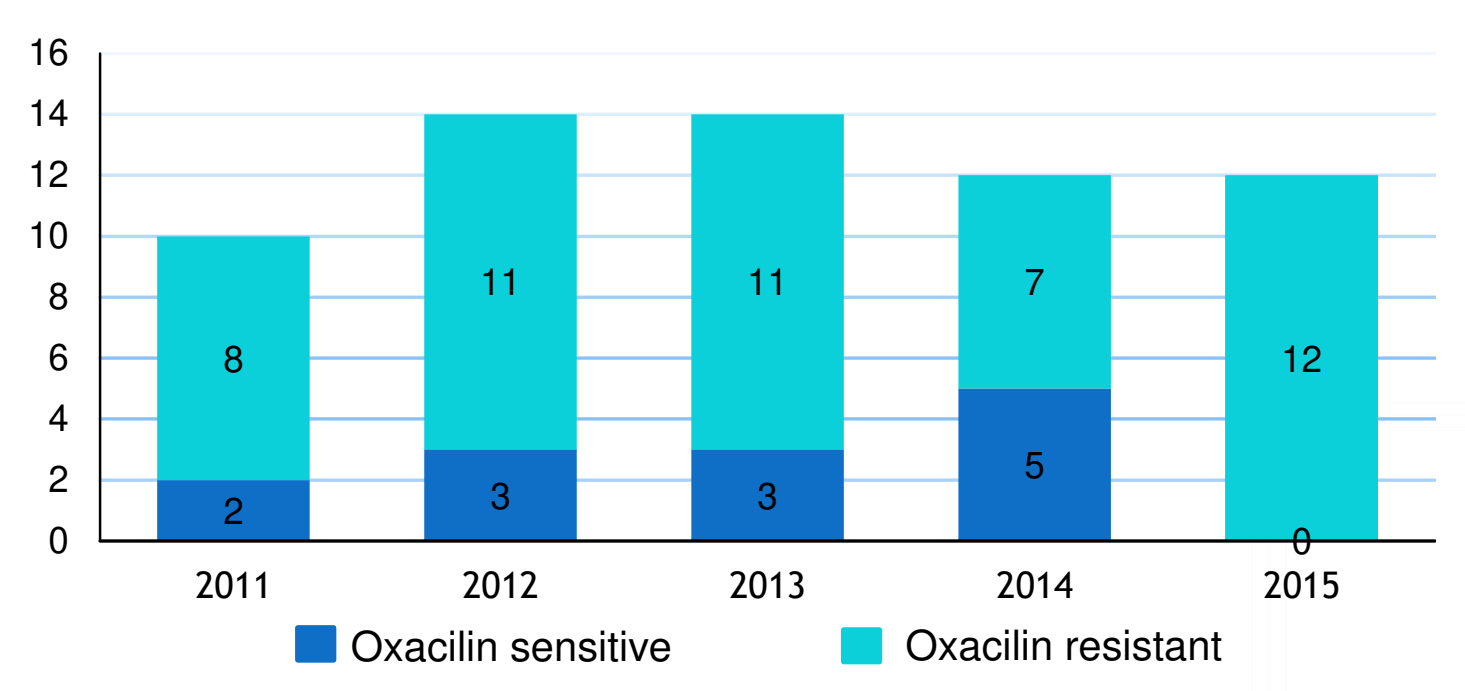

GRAPHIC3: Number of antibiotic resistant Klebsiella strains between 2011 and 2015 (n)

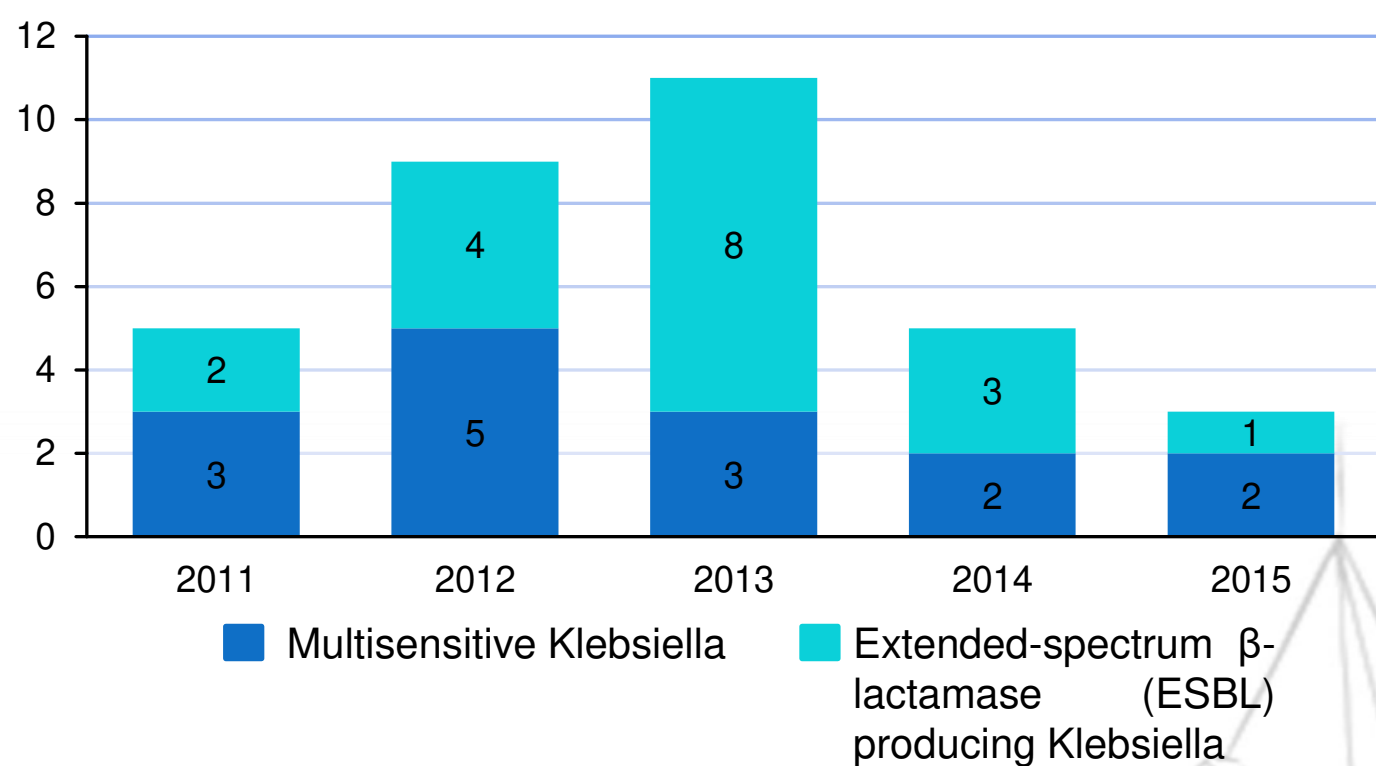

GRAPHIC1: Number of the pathogens isolated from late onset neonatal sepsis's blood cultures between 2011 and 2015 (n)
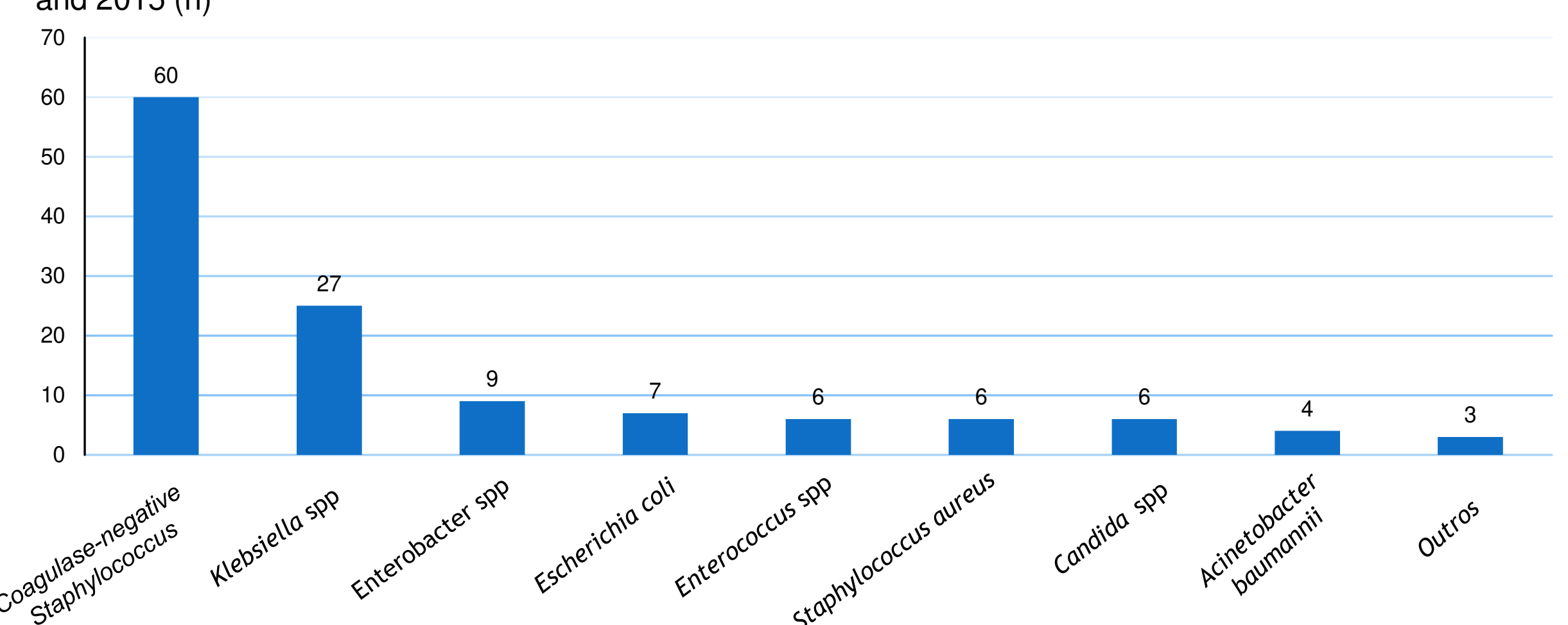

\section{CONCLUSIONS}

Most of the bacteria causing late-onset neonatal sepsis were antibiotic-resistant strains. Strategies to improve the management of these neonates remain a concern to reduce healthcareassociated infection and the antibiotics resistance. 